\title{
Study on the Chemistry Identification and Assessment of Antioxidant and Antibacterial Activity of the Biologically Active Constituents from the Roots of Arnebia Euchroma for Promising Application in Nanomedicine and Pharmaceutical
}

\author{
Fatemeh Asghari 1(D), Hosein Ghanbari ${ }^{1}$ (D), Hamid Reza Moghimi ${ }^{2}$ (D), Nasrin Takzaree ${ }^{3}$, Houra \\ Nekounam ${ }^{1}$, Reza Faridi-Majidi 1,*(D) \\ 1 Department of Medical Nanotechnology, School of Advanced Technologies in Medicine, Tehran University of Medical \\ Sciences, Tehran, Iran \\ 2 Department of Pharmaceutics, School of Pharmacy, Shahid Beheshti University of Medical Sciences, Tehran, Iran \\ 3 Department of Anatomy, School of Medicine, Tehran University of Medical Sciences, Tehran, Iran \\ * Correspondence: refaridi@ sina.tums.ac.ir (R.F.M.);
}

Scopus Author ID 55991162500

Received: 28.04.2021; Revised: 10.06.2021; Accepted: 14.06.2021; Published: 13.08.2021

\begin{abstract}
The recent work aims to investigate different extracts of A. euchroma as a medicinal plant and evaluate their phytochemicals screening, chemical compositions, total phenols content, antioxidant and antimicrobial activities. The plant's roots were extracted with various solvents: ethanol, n-Hexane, and chloroform through the maceration method at ambient temperature for several days. All extracts were filtered and evaporated to dryness using a rotary evaporator and vacuum oven. The chemical compositions, spectroscopy analysis, total phenols, antioxidant and antimicrobial activities of three prepared extracts were evaluated by Liquid Chromatography-Mass Spectrometry (LC-MS), UV-vis, High-performance thin-layer chromatography (HPTLC), Folin-Ciocalteu reagent (FCR), 2,2-diphenyl1-picrylhydrazyl (DPPH), and MIC and MBC methods, as well as the structure and surface morphologies of the bacteria after and before treatment, were imaged by Scanning Electron Microscopy (SEM). The phytochemical screening demonstrated that the extracts contain tannins, saponin, alkaloid, and anthraquinone. This result was supported via LC-MS analysis, which confirmed the existence of several components. The highest amount of phenols was detected in n-hexane extract, and the lowest was in chloroform. All extracts had good antioxidant activity, with IC50 values of $3.9 \mu \mathrm{g} / \mathrm{ml}$ for ethanol and chloroform extract and $7.8 \mu \mathrm{g} / \mathrm{ml}$ for n-hexane in the DPPH assay. The extracts inhibited both Gram-positive and Gram-negative bacteria's growth at a 300-700 $\mu \mathrm{g} / \mathrm{ml}$ MIC. LC-MS analysis showed the presence of phenolic compounds, which had high antioxidant activity. It could be used as a potent antioxidant and antibacterial agent with remarkable prospects in pharmaceutical and nanoformulation.
\end{abstract}

Keywords: active constituents; antioxidant; antibacterial; medicinal plant; phytochemical screening.

(C) 2021 by the authors. This article is an open-access article distributed under the terms and conditions of the Creative Commons Attribution (CC BY) license (https://creativecommons.org/licenses/by/4.0/).

\section{Introduction}

Arnebia Euchroma (Royle) I.M. Johnst (A. euchroma) belongs to the family of Boraginaceae, which has been distributed in Asia and the drier regions of Northern Africa [1, 2]. Boraginaceae is described in about 100 genera and 2000 tropical and temperate regions [3, 4]. There are several species of Arnebia, but from these species, A. euchroma possesses the 
most amount of shikonin and its derivatives. The root of A. euchroma contains a dark purplishred/purplish-brown color that looks arid and contracted. Many species A. euchroma have been investigated concerning their bioactive chemical compounds due to common medicinal and other relevant applications like pharmaceuticals. Research findings confirm that the $A$. euchroma species have antifungal [5], antibacterial [6, 7], antioxidant [8], anti-inflammatory [1], wound healing [9], and anticancer activities [10], which are related to the naphthoquinone compound. These notable biological activities are the chiral pairs of shikonin and alkannin, which are useful pharmaceutical substances [11].

Herbal medicine has recently obtained considerable popularity due to fewer side effects and simple accessibility than synthetic drugs. From a medicinal standpoint, A. euchroma is one of the most extensively investigated due to shikonin and alkaline and their derivatives. Naphthoquinones are principally utilized as coloring pigments in cosmetics and healthcare in the food and textile industry $[12,13]$. The anticancer effect of shikonin has been confirmed in a clinical trial via meaningfully decreased tumor growth in late-stage lung cancer patients without further therapeutic options [14]. Naphthoquinone compounds have been utilized in wound healing studies due to re-epithelisation, angiogenesis, and granulation tissue formation promotion effects $[15,16]$. The extraction of active constituents from medicinal plants is mostly performed through maceration or solvent extraction. Most studies about this plant have been performed on phytochemical investigations [17], which were resulted in the isolation of naphthoquinones [18, 19], monoterpenes [20], phenols, and pyrrolizidine alkaloids [21]. Resistance to antibiotics is growing with harmful pathogens, which have become a fundamental problem in the hospital care system [22, 23]. Besides, the infections can prevent wound healing and also enhances the risk of scar formation. Therefore, the development of novel antimicrobial drugs can play a vital role in resisting drug-resistant pathogens. Herbal medicine and its secondary metabolites have had tremendous remedial potential for their use as medicines since last years. Also, research findings confirm that traditional herbs affect different pathogenic microorganisms [24]. Singh, L.K. et al. have demonstrated the biomedicinally potential of a bioactive marker which has been isolated from the n-hexane root extract of A. euchroma against various vancomycin-resistant Enterococcus [6]. Also, the other study has been conducted by Damianakos, H. et al. on antimicrobial activities of all isolated pigment compounds from $A$. euchroma. Their results confirm the antimicrobial activity of this plant [11]. Reactive Oxygen Species (ROS) are known as several reactive molecules and free radicals. Many studies have been performed on ROS in recent years. Their research findings have confirmed that these oxygen species can play a vital role in protein, cholesterol, and DNA which will cause the progression of diseases and their complications [25, 26]. Besides oxygen, free radicals are one of the main factors which can cause different diseases [27]. In addition, ROS will make an imbalance in biological systems, which are meaningfully associated with intracellular reduction-oxidation (redox). Hence antioxidant materials play a crucial role against ROS. Medicinal herbs can be effect antioxidant activities because of their secondary metabolites. Several types of research have been conducted on raw extracts or isolated compounds from herbals and results have determined that they are more likely effective compared with synthetic antioxidants $[13,28]$. Therefore, one of the potential sources of natural antioxidants is medicinal herbs.

In this research, we have focused on the possible future application of A. euchroma in nanotechnology and pharmaceutical-based on its antibacterial and antioxidant activity, locally 
known as 'Havachobeh' in Iran. Therefore, our study aimed to carry out phytochemical screening and ascertain the total phenolic contents and antioxidant activities by DPPH, antibacterial activity via MIC and MBC method of the ethanol, chloroform, and n-hexane extracts from the roots of A. euchroma. The extracts' compositions, fingerprints of various secondary metabolites, and absorption peak of extracts have been analyzed via LC/MS, HPTLC, and UV-VIS analysis.

\section{Materials and Methods}

Dimethyl sulfoxide (DMSO) (C2H6OS, 99.5\%, Sigma-Aldrich, USA), Diphenylpicrylhydrazyl (DPPH) (C18H12N5O6, SigmaAldrich, USA), Ethanol (EtOH) (C2H5OH, 96\%, Merck Chemicals, Germany), Chloroform (CHCl3, Merck Chemicals, Germany), and n-Hexane (C6H14, Merck Chemicals, Germany), were all purchased and used without any additional purification. Also, A. euchroma was purchased from the Herb Material Market of Kerman Province, Iran, and approved by Dr. M. Vazirian, Tehran University of Medical Sciences.

\subsection{Preparation of extract.}

The dried and powdered roots of A. euchroma $(200 \mathrm{~g})$ were extracted by the maceration method with three different solvents: ethanol, chloroform, and n-hexane $(1000 \mathrm{~mL})$ that; each sample was stirred at room temperature for seven days. Then, it was concentrated at $40{ }^{\circ} \mathrm{C}$ using a rotary evaporator. The concentrated extracts were dried in a vacuum oven (Memmert, Schwabach, Germany) at $50{ }^{\circ} \mathrm{C}$ and a vacuum pressure of $65 \mathrm{mb}$. Subsequently, all the extracts were weighed and stored at $-20^{\circ} \mathrm{C}$ until their utilization.

\subsection{Phytochemicals screening.}

The various plant extracts were evaluated for phytochemical content's presence to find different groups of constituents to check whether they exist or not in the extracts using the following standard methods [29-31].

\subsubsection{Detection of alkaloids.}

Each dry extract powder $(10 \mathrm{mg})$ was dissolved in $10 \mathrm{ml}$ of acetic acid $10 \%$ in ethanol and stored 24 hours at room temperature. Then all samples were filtered and concentrated with the rotary evaporator at $45^{\circ} \mathrm{C}$. Few drops of Mayer's reagent (mercuric chloride and potassium iodide dissolved in distilled water) were added gently to the samples appearance of whitecolored precipitate determines the presence of alkaloids.

\subsubsection{Detection of tannins.}

$10 \mathrm{mg}$ of each powdered dry extract were added to $10 \mathrm{ml}$ of distilled water; the mixture is then filtered and added $3 \mathrm{ml} \mathrm{NaCl} 10 \%$. A few drops of $5 \%$ ferric chloride solution are added to the filtrated samples one hour later. The appearance of a blue-black, green or blue-green precipitate ascertains the existence of tannins. 


\subsubsection{Detection of saponins.}

$10 \mathrm{mg}$ of powdered dry extracts were mixed with $10 \mathrm{ml}$ of distilled water and then boiled, filtered, and stored $30 \mathrm{~min}$ at room temperature. The all filtrated sample was mixed again with $3 \mathrm{ml}$ of distilled water and shaken for $5 \mathrm{~min}$. The occurrence of foam after shaking confirms the existence of saponins.

\subsubsection{Detection of anthraquinones.}

$10 \mathrm{mg}$ of each powdered dry extract were weighed and mixed with $5 \mathrm{ml}$ of HCL $10 \%$. Then all samples were heated $80^{\circ} \mathrm{C}$ in a bain-marie for $15 \mathrm{~min}$. The samples were filtered and added $1 \mathrm{ml}$ ammonia 10\%, and heated again. The appearance of pink, violet, or red color designated the anthraquinones' existence in the ammonia phase.

\subsection{UV-Vis absorbance Spectroscopy.}

UV-Vis absorbance spectroscopy was utilized to analyze the extracts, prominent peak (Bio Aquarius CE 7250, United Kingdom). Sample analysis was carried out at room temperature. Total spectrum analysis from $200 \mathrm{~nm}$ to $900 \mathrm{~nm}$ was performed as it promotes understanding different peaks occurring due to varied components existing in the extract and obtaining the ' $K$ max' wavelength.

\subsection{Liquid Chromatography-Mass Spectrometry (LC-MS) Analysis.}

LC-MS studies of the different extracts of A. euchroma were performed applying a Shimadzu LCMS 2010 ASystem consisting of a degasser, binary pump, autosampler, and column heater. The column outlet was coupled to a Thermo fleet (LCQ-Fleet) Ion Trap mass spectrometer equipped with an ESI ion source. Data acquisition and mass spectrometric assessments were performed in a personal computer with Data Analysis software (Shimadzu LC-MS 2010 A). To chromatographic separation, a Phenomenex luna 5- $\mu \mathrm{m}$ C8 column (4.6 × $250 \mathrm{~mm}$ ) was employed. The column was kept at $95 \%$ Solvent A (Acetonitrile $0.1 \%$ Formic Acid) and 5\% Solvent B (H_2 O 0.1\% Formic Acid) for $1 \mathrm{~min}$, followed by an $11 \mathrm{~min}$ step gradient from $5 \% \mathrm{~B}$ to $100 \% \mathrm{~B}$, next it was held for 4 min with $100 \% \mathrm{~B}$. Ultimately, elution was performed with a linear gradient from $100 \% \mathrm{~B}$ to $5 \% \mathrm{~B}$ for $2 \mathrm{~min}$. The flow rate was set at $0.25 \mathrm{ml} / \mathrm{min}$ and also the injection volume $5 \mu \mathrm{l}$. The following parameters were applied during the MS test: to electrospray ionization with positive ion polarity, the capillary voltage was set to $30 \mathrm{~V}$, the capillary temperature to $280^{\circ} \mathrm{C}$, the nebulizer pressure to $40 \mathrm{psi}$, and the drying gas flow rate to $1.2 \mathrm{~L} / \mathrm{min}$.

\subsection{High-performance thin-layer chromatography (HPTLC) studies.}

The extract compounds were assessed through an HPTLC system (CAMAG, Muttenz, Switzerland) with TLC visualizer linked to vision CATS software. A plant crude extract was dissolved in DMSO (dimethyl sulphoxide) $10 \mathrm{mg} / \mathrm{ml}$. The filtered solutions were applied to silica gel 60F 254 on HPTLC Plate $5 \times 10 \mathrm{~cm}$, and the conditions were syringe delivery speed of $10 \mathrm{~s} / \mu \mathrm{l}$; injection volumes of $2 \mu \mathrm{l}$ for plant extract. The HPTLC plate was developed in a horizontal chamber after saturation in toluene: ethyl acetate mobile phase $(85: 15 \mathrm{v} / \mathrm{v})$ for $5 \mathrm{~min}$ at room temperature. The length of the chromatograms was $75 \mathrm{~mm}$ from the applied spots. The developed plate was allowed to dry for $1 \mathrm{~min}$ before derivatizing with Derivatisation reagent: 
anisaldehyde-sulfuric acid and methanol-sulfuric acid (2\%). The plate before and after derivatization was observed under a UV lamp at 254 and $365 \mathrm{~nm}$.

\subsection{Measurement of total phenolic content.}

To determine the total phenolic content of extracts was used the Folin-Ciocalteu method [32,33]. The concentration of extract samples was prepared $1 \mathrm{mg} / \mathrm{ml}$ in methanol, and also the $10 \%$ Folin-Ciocalteu's reagent (FCR) and 7.5\% (w/v) sodium carbonate (NaHCO3) were prepared with deionized water. Based on this method, $500 \mu 1$ of extract solution was carried in a tube and then added $2.5 \mathrm{ml}$ of FCR reagent and $2.5 \mathrm{ml} \mathrm{NaHCO} 3$ solution, and it was blended well and left in a dark place for 2 hours. Likewise, the blank sample was provided without the addition of extract samples. UV spectrophotometer absorbance was measured at 765 . The total phenolic content was estimated $(\mu \mathrm{g} / \mathrm{ml})$ from the calibration curve of gallic acid. The phenols' content in extracts was presented in terms of gallic acid equivalent ( $\mu \mathrm{g}$ of $\mathrm{GA} / \mathrm{mg}$ of dried extract). The following equation was applied for the computation of the total amount of phenols:

$$
\text { Total phenol }=\text { absorption }(\mathrm{y}) / 0.00147
$$

\subsection{Determination of antioxidant capacity.}

\subsubsection{DPPH assay.}

The antioxidant activity of $A$. euchroma extracts was measured by using the 1,1 diphenyl-2-picryl hydrazyl (DPPH) method with some modifications [34, 35]. This property of the radical is utilized to display the antioxidant activity of the extract. Briefly, in each microtube, $1 \mathrm{ml}$ DPPH $0.1 \mathrm{mM}$ solution in methanol was mixed with $1 \mathrm{ml}$ various concentration of extracts solutions $(250 \mu \mathrm{g} / \mathrm{ml}-0.5 \mu \mathrm{g} / \mathrm{ml})$ diluted in methanol. These mixtures were shaken gently and incubated at a dark place for $30 \mathrm{~min}$ at room temperature. The absorbance was measured at $516 \mathrm{~nm}$ against the blank sample. The scavenging activity of the extracts was estimated as the inhibition percentage by applying the following equation:

$$
\text { \%DPPH scavenging effect: ((A0-As)/A0) *100 }
$$

where A0 is the absorbance of the control solution and As is the absorbance of the sample. High inhibition percentage displays the vigorous antioxidant activity of the samples.

\subsubsection{Total Antioxidant Capacity (TAC) assay.}

The total antioxidant capacity of various extracts was measured using a ferric reducing/ antioxidant power (FRAP) assay through Naxifer ${ }^{\mathrm{TM}}$ Total Antioxidant Capacity (TAC) Assay Kit (Navand Salamat, Iran). FRAP assay assesses the change in absorbance at $593 \mathrm{~nm}$ due to the constitution of a blue-colored FeII-tripyridyltriazine compound from colorless oxidized FeIII form via the action of electron-donating antioxidants [36]. The standard curve was prepared using different concentrations of the standard solution $(0-1 \mathrm{mmol} / \mathrm{L})$. All solutions and reagents were used on the day of preparation. In the FRAP assay, the antioxidant yield of various extracts under the test was measured regarding the response signal given through a $\mathrm{Fe}^{2+}$ reagent in the known concentration kit, indicating a one-electron exchange reaction. The results of the experiment were adjusted for dilution and expressed in $\mathrm{mmol} \mathrm{Fe}^{2+} / \mathrm{L}$. All extract was weighed and dissolved in methanol $(10 \mathrm{mg} / \mathrm{ml})$ then incubated at $37{ }^{\circ} \mathrm{C}$ for 30 minutes. Based 
on the TAC kit protocol, $5 \mu$ l of extract solution was carried in a 96 well plate and then added $250 \mu \mathrm{l}$ of TAC kit reagent, and it was pipetted well and left in a dark place for 10 minutes. The absorbance was measured at $593 \mathrm{~nm}$ by plate reader. The total antioxidant capacity was estimated ( $\mathrm{mmol} \mathrm{Fe} \mathrm{F}^{2+} / \mathrm{L}$ ) from the calibration curve of the standard solution. All extracts to be analyzed were diluted enough to fit within the linearity range. All samples were carried out in triplicate.

\subsection{Antibacterial activity.}

The extracts' antibacterial activity was estimated via minimum inhibitory concentration (MIC), and minimum bactericidal concentration (MBC) of different extracts were specified by the microtiter broth-dilution method against two Gram-positive Staphylococcus aureus and Staphylococcus epidermidis and two Gram-negative E. coli and Pseudomonas aeruginosa bacterial strains. This test was done under defined test conditions through inoculating $100 \mu \mathrm{l}$ $0.5 \mathrm{McFarland}$ turbidity of each bacteria (nearly $2 \times 108 \mathrm{CFU} \mathrm{ml}-1$ ) to Mueller-Hinton Broth, and the bacterial suspension was swabbed via the sterile swab. MIC was obtained through inoculating the bacteria into a series of wells with two-fold dilutions of the different extracts in concentrations ranging from 1000-1 $\mu \mathrm{g}$ ). After incubation time, the lowest concentration of the antimicrobial agent, which visually prevents the microorganism's growth, was reported as MIC. After the extract's MIC designation, aliquots of $100 \mu 1$ from samples that measured no visible bacterial growth were seeded in Muller- Hinton agar plate. Any inhibited but not killed in the MIC test now have a chance to grow because the extracts have been diluted notably. After 18-24 hour incubation, the lowest concentration of antimicrobial agent that has reduced the number of colonies by $99.9 \%$ is determined as MBC. All designations were done in triplicate.

\subsection{Scanning Electron Microscopy (SEM) imaging of bacteria.}

The structure and surface morphologies of the bacteria were imaged by SEM (Philips XL 30, Netherlands) after gold coating at a voltage of $25 \mathrm{KV}$ was applied to assess the bacteria's appropriate morphology. Before processing for SEM imaging, all specimens must be fixed. Fixation conditions can differ according to the target bacteria and type of sample. Moreover, optimal fixation results in good quality SEM images and the maintenance of integrity and morphological detail. To fixation, transfer enough bacteria culture to a $1.5 \mathrm{~mL}$ microcentrifuge tube and then centrifuge at $4000 \mathrm{rpm}$ for $15 \mathrm{~min}$. After centrifuging for $15 \mathrm{~min}$ to settle, the bacterial pellet is created at the bottom of the tube. Then remove supernatant and add $4 \%(\mathrm{v} / \mathrm{v})$ formaldehyde or paraformaldehyde directly to the pellet and allow to incubate for $30 \mathrm{~min}$. Paraformaldehyde is commonly proper for bacteria fixation. After finishing incubation time with paraformaldehyde, remove the fixative solvent gently and wash the fixed pellet three times with $1 \mathrm{~mL}$ of phosphate buffer $\mathrm{pH} 7.0$ at room temperature. Dehydrate all samples while maintaining continuous immersion by using a different graded ethanol concentration 30\%, $50 \%, 70 \%, 90 \%$, and two times $100 \%$ for 5-10 min in a volume of $1 \mathrm{ml}$. For each step, remove ethanol and add the next series. Be careful not to remove the pellet. Maintain the pellet in the $1.5 \mathrm{~mL}$ microcentrifuge tube with just sufficient $100 \%$ ethanol to cover the bacteria sample before drying. 


\section{Results and Discussion}

\subsection{Extraction yield.}

The extraction yields of A. euchroma are determined in Table 1. After ethanolic, chloroform, and n-hexane extractions, ethanolic extract provided a higher yield of $11.5 \%$ than the others. The lower variation in the yields of extractions can be ascribed to the various extractable component availability due to different chemical compositions of solvent. There are no adequate studies in the literature about yields of $A$. euchroma in other extraction methods. The extraction yield was calculated by applying the equation of the extract's weight into the dry plant's weight.

Table 1. The weight of each residue obtained after extraction by the different solvent.

\begin{tabular}{l|c|c} 
Extract & $\begin{array}{c}\text { Weight } \\
\text { (gram) }\end{array}$ & $\begin{array}{c}\text { Yield } \\
(\mathbf{\%})\end{array}$ \\
\hline Ethanol & 23 & 11.5 \\
\hline Chloroform & 4.7 & 9.4 \\
\hline n-Hexane & 1.7 & 3.4
\end{tabular}

\subsection{Phytochemical screening.}

The phytochemical analysis of prepared three extracts was assessed based on a wellestablished method reported by literature [30, 37]. The results of phytochemical analysis have been presented in Table 2. According to the phytochemical analysis of three extracts in Table 2 , the results demonstrate that the ethanol extract contains alkaloids, tannins, and anthraquinones. The chloroform extract has the only tannin, and the hexane extract possesses alkaloids, tannins, and saponins.

Table 2. Phytochemical analysis of various crude extracts of A. euchroma.

\begin{tabular}{l|c|c|c} 
Phytochemical & Ethanol & $\begin{array}{c}\text { n- } \\
\text { Hexane }\end{array}$ & Chloroform \\
\hline Alkaloid & + & + & - \\
\hline Saponins & - & + & - \\
\hline Tannins & + & + & + \\
\hline Anthraquinone & + & - & -
\end{tabular}

\subsection{UV-Vis absorbance Spectroscopy.}

The UV-Vis spectrum of A. euchroma extract (Figure 1) in three different solvents demonstrates absorption peaks at $\lambda \max 543.5$ and 575.5 for ethanol, 495, 526.5, and 575 for chloroform, and 490.5, 524.5, 545.5 and $563.5 \mathrm{~nm}$ for n-hexane.
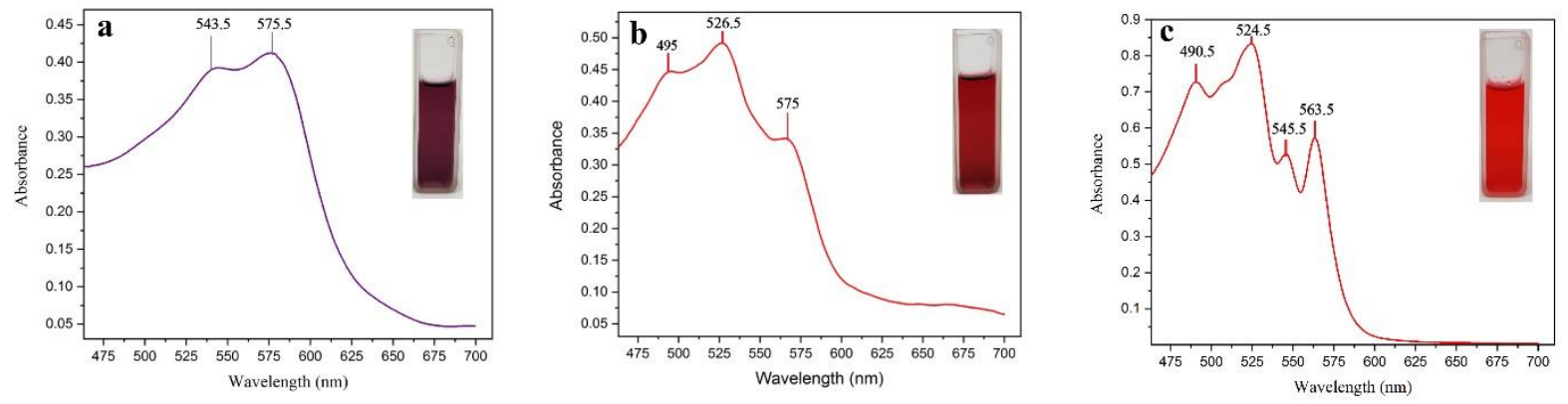

Figure 1. The UV-Vis spectrum of A. euchroma extract (a) ethanol extract; (b) chloroform extract; (c) n-hexane extract. 
3.4. Liquid Chromatography-Mass Spectrometry (LC-MS) studies.

LC-MS analysis of three different extracts of A. euchroma has detected several peaks with the retention time 24.310 and 26.410 for ethanol extract, 1.610, 1.910, 2.027, 20.693, $24.243,24.718,25.860,25.893,27.760,27.777,27.827,28.493$ and 29.543 for n-hexane. No peak was detected in the chloroform extract. Each peak shows candidates' mass (m/z) (Figure 2 and Tables 3-4). The LC-MS spectrums were interpreted using a spectrum database for organic compounds in SDBS web National Institute of Advanced Industrial Science and Technology (AIST) [38]. The spectrum interpretation results on three different extracts of $A$. euchroma confirm substances with the various retention times mentioned in Table 3-4. These results were confirmed by the chromatogram pattern as fig. 2 mentioned. The LC/MS analysis enabled us to identify 14 compounds in n-Hexane extracts of A. euchroma and 2 compounds in Ethanol extracts of A. euchroma separately which was mentioned in (Table3-4), including n-Hexan extracts compounds: strontium chloranilate, p-chlorobenzoyl isothiocyanate, N,N'(tetramethylenebis(oxy-p-phenylenetrimethylene))diacetamide, 2-chloroanthraquinone, triethylstannyl acrylate, 4,4'-diiodo-3,3'-dimethylbiphenyl, 2,4,6-triphenylpyrylium 1naphthalenesulfonate, 7-chloro-1-methyl-5-phenyl-2,3-dihydro-1H-1,4-benzodiazepine, 3oxo-5beta-cholestan-2-yl propionate, (2S,4R)-N-((1S)-2-(benzyl(methyl)amino)-1-(2naphthylmethyl)-2-oxoethyl)-4-hydroxy-1-((1-methyl-1H-indol-3-yl)carbonyl)-2-

pyrrolidinecarboxamide, benzyltripropylammonium chloride, 3,3-bis(ethylthio)-2betahydroxy-5beta-cholan-24-oic acid, bis((isobutylthio)acetato)copper(II), 2,3,4,5tetraphenylpyrrole and Ethanol extracts compounds: triethylstannyl acrylate and transtriphenyl(1-propenyl)phosphonium chloride. The LC/MS analysis of A. euchroma extract reflects the identical phenolic profile of n-Hexane extracts. The concentrations of these phenolic compounds in n-Hexane extract were higher than those in other extracts, as proved in the total phenolic content assay. Phenolic compounds related to health benefits expand shelf life by avoiding oxidative deterioration of food and maintaining food colors, flavors, and nutritional values. Therefore these natural sources of medicinal compounds are beneficial in the pharmaceutical and also in food industries.

(a)

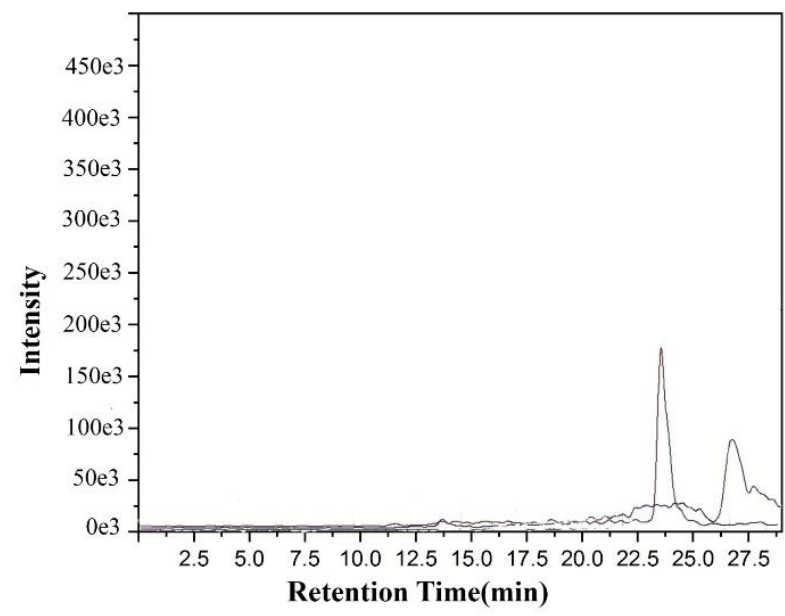

(b)

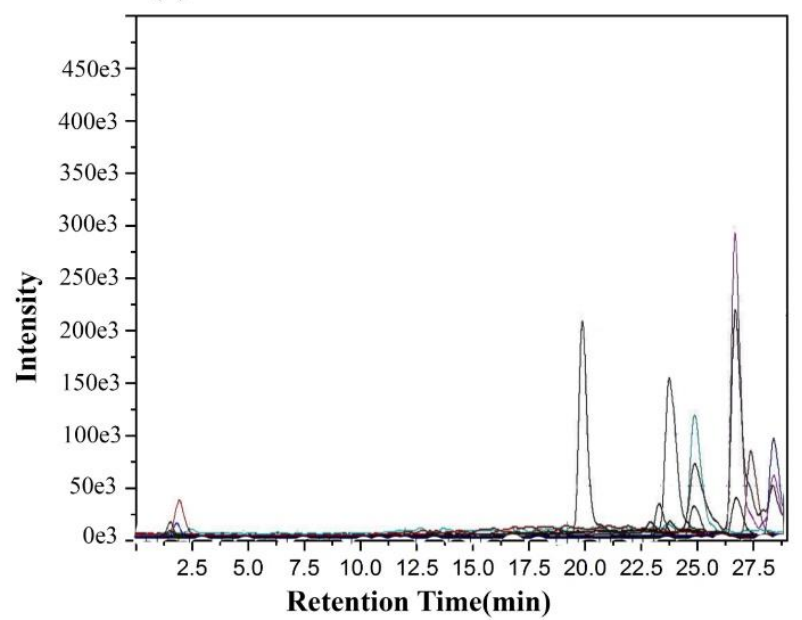

Figure 2. Mass chromatogram of A. euchroma extracts; (a) Ethanol extract chromatogram which was detected two-component; (b) n-Hexane extract chromatogram, which was seen fourteen components. 
Table 3. LC-MS profile of n-Hexane extracts of A. euchroma.

\begin{tabular}{|c|c|c|c|c|c|}
\hline $\begin{array}{c}\text { Peak } \\
\text { no. }\end{array}$ & $\begin{array}{c}\text { RT } \\
(\mathbf{m i n})\end{array}$ & Proposed Compound & Formula & $\begin{array}{c}\text { Measured } \\
(\mathbf{m} / \mathbf{z})\end{array}$ & $\begin{array}{c}\text { Candidate } \\
\text { mass }\end{array}$ \\
\hline 1 & 2.027 & strontium chloranilate & $\mathrm{SrC}_{6} \mathrm{Cl}_{2} \mathrm{O}_{4}$ & 294.60 & 294.6 \\
\hline 2 & 1.910 & p-chlorobenzoyl isothiocyanate & $\mathrm{C}_{8} \mathrm{H}_{4} \mathrm{ClNOS}$ & 197.65 & 197.6 \\
\hline 3 & 1.610 & $\begin{array}{c}\mathrm{N}, \mathrm{N} \text { '-(tetramethylenebis(oxy-p- } \\
\text { phenylenetrimethylene))diacetamide }\end{array}$ & $\mathrm{C}_{26} \mathrm{H}_{36} \mathrm{~N}_{2} \mathrm{O}_{4}$ & 440.60 & 440.6 \\
\hline 4 & 1.610 & 2-chloroanthraquinone & $\mathrm{C}_{14} \mathrm{H}_{7} \mathrm{ClO}_{2}$ & 242.65 & 242.6 \\
\hline 5 & 24.243 & triethylstannyl acrylate & $\mathrm{SnC}_{9} \mathrm{H}_{18} \mathrm{O}_{2}$ & 276.90 & 276.9 \\
\hline 6 & 20.693 & 4,4'-diiodo-3,3'-dimethylbiphenyl & $\mathrm{C}_{14} \mathrm{H}_{12} \mathrm{I}_{2}$ & 433.60 & 434.0 \\
\hline 7 & 24.718 & $\begin{array}{c}\text { 2,4,6-triphenylpyrylium 1- } \\
\text { naphthalenesulfonate }\end{array}$ & $\mathrm{C}_{33} \mathrm{H}_{24} \mathrm{O}_{4} \mathrm{~S}$ & 516.60 & 516.6 \\
\hline 8 & 27.777 & $\begin{array}{l}\text { 7-chloro-1-methyl-5-phenyl-2,3- } \\
\text { dihydro-1H-1,4-benzodiazepine }\end{array}$ & $\mathrm{C}_{16} \mathrm{H}_{15} \mathrm{ClN} 2$ & 270.80 & 270.8 \\
\hline 9 & 25.860 & $\begin{array}{l}\text { 3-oxo-5beta-cholestan-2-yl } \\
\text { propionate }\end{array}$ & $\mathrm{C}_{30} \mathrm{H}_{50} \mathrm{O}_{3}$ & 458.70 & 458.7 \\
\hline 10 & 25.893 & $\begin{array}{c}\text { (2S,4R)-N-((1S)-2- } \\
\text { (benzyl(methyl)amino)-1-(2- } \\
\text { naphthylmethyl)-2-oxoethyl)-4- } \\
\text { hydroxy-1-((1-methyl-1H-indol-3- } \\
\text { yl)carbonyl)-2- } \\
\text { pyrrolidinecarboxamide }\end{array}$ & $\mathrm{C}_{36} \mathrm{H}_{36} \mathrm{~N}_{4} \mathrm{O}_{4}$ & 588.90 & 588.7 \\
\hline 11 & 27.760 & benzyltripropylammonium chloride & $\mathrm{C}_{16} \mathrm{H}_{28} \mathrm{ClN}$ & 269.800 & 269.8 \\
\hline 12 & 27.827 & $\begin{array}{l}\text { 3,3-bis(ethylthio)-2beta-hydroxy- } \\
\text { 5beta-cholan-24-oic acid }\end{array}$ & $\mathrm{C}_{28} \mathrm{H}_{48} \mathrm{O}_{3} \mathrm{~S}_{2}$ & 496.80 & 496.8 \\
\hline 13 & 28.493 & bis((isobutylthio)acetato)copper(II) & $\begin{array}{c}\mathrm{C}_{12} \mathrm{H}_{22} \mathrm{CuO}_{4} \mathrm{~S}_{2} \\
2 \mathrm{H}_{2} \mathrm{O}\end{array}$ & 358.00 & 358.0 \\
\hline 14 & 29.453 & 2,3,4,5-tetraphenylpyrrole & $\mathrm{C}_{28} \mathrm{H}_{21} \mathrm{~N}$ & 371.70 & 371.5 \\
\hline
\end{tabular}

Table 4. LC-MS profile of Ethanol extracts of A. euchroma.

\begin{tabular}{c|c|c|c|c|c}
$\begin{array}{c}\text { Peak } \\
\text { no. }\end{array}$ & $\begin{array}{c}\text { RT } \\
(\mathbf{m i n})\end{array}$ & Proposed Compound & Formula & $\begin{array}{c}\text { Measured } \\
(\mathbf{m} / \mathbf{z})\end{array}$ & $\begin{array}{c}\text { Candidate } \\
\text { mass }\end{array}$ \\
\hline 1 & 24.310 & triethylstannyl acrylate & $\mathrm{C}_{9} \mathrm{H}_{18} \mathrm{O}_{2} \mathrm{Sn}$ & 276.90 & 276.9 \\
\hline 2 & 26.410 & $\begin{array}{c}\text { trans-triphenyl }(1- \\
\text { propenyl)phosphonium } \\
\text { chloride }\end{array}$ & $\mathrm{C}_{21} \mathrm{H}_{20} \mathrm{ClP}$ & 338.80 & 338.8 \\
& $\begin{array}{c}\mid \\
\text { chlon }\end{array}$ & &
\end{tabular}

\subsection{High-performance thin-layer chromatography (HPTLC) studies.}

The method which has been used is a normal phase HPTLC method. The stationary phase was silica gel 60 F254 that was pre-coated on the aluminum sheet for the analysis. The mobile phase included toluene- ethyl acetate -formic acid (7:3:1) for detecting apolar flavonoids, toluene- methanol-diethylamine (8:1:1) for detecting alkaloids, and toluene- ethyl acetate $(85: 15)$ for finding terpenoid- saponin, which exhibited good separation of from the other phytochemicals of A. euchroma. The fluorescence quenching effect was enhanced by quenching of fluorescence due to UV light normally ranging at 200-400 nm to detect separated compounds on the sorbent layers. F254 is described as phosphorescence quenching. F254 fluorescent indicator is excited with UV wavelength at $254 \mathrm{~nm}$ and emits green fluorescence. The leading cause of this quenching is all compounds with conjugated double bonds. Important compounds could be detected under $254 \mathrm{~nm}$, including coumarins, anthraglycosides, flavonoids, propylphenols in essential oils, several alkaloid types like isoquinoline, indole, and quinoline alkaloids, etc. [39, 40]. Derivatisation reagents used in this method include dragendroff reagent, natural products, anisaldehyde sulphuric acid, and methanol-sulfuric acid (2\%) for detecting alkaloids, flavonoids, bitter principle- saponin- essential oil and anthraquinones, respectively (Figure 3). Dragendroff reagent can create a red-brown zone (Vis), and also natural products reveal intense yellow, orange, and green fluorescent zones in UV $366 \mathrm{~nm}$. Anisaldehyde sulphuric acid displays red-brown, yellow-brown, dark green Zone (Vis) for bitter principle, coloured zones (Vis) for saponin and blue, brown or red zones (Vis) 
for essential oil. Methanol-sulfuric acid can also expose red zones (vis) and red fluorescence UV $366 \mathrm{~nm}$ for anthraquinone [39].
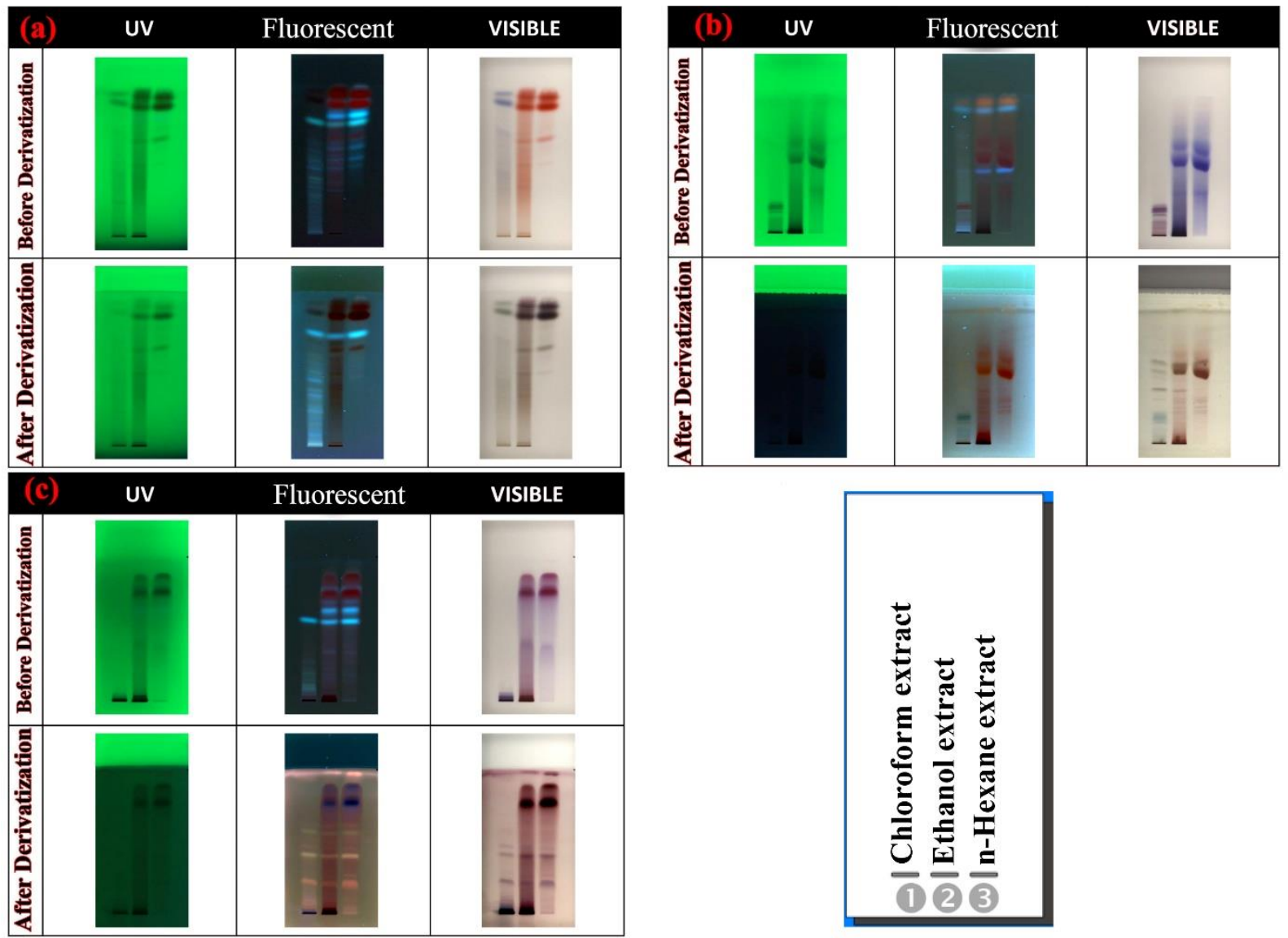

Figure 3. HPTLC fingerprinting for plant extract; (a) Apolar flavonoids; (b) Alkaloids; (c) terpenoid- saponin.

\subsection{Total phenolic content (TPC).}

The three extract's total phenolic contents measured via the Folin-Ciocalteu method were reported as gallic acid equivalents [41]. Among the three different extracts, the n-Hexane extract was comprising the highest level of total phenolic content $(407.41 \pm 66.01 \mathrm{GAE} \mu \mathrm{g} / \mathrm{mg})$ followed by Ethanol extract $(225.98 \pm 1.24 \mathrm{GAE} \mu \mathrm{g} / \mathrm{mg})$ and Chloroform extract $(123.81 \pm 8.67$ GAE $\mu \mathrm{g} / \mathrm{mg}$ ). So the lowest TPC was found in Chloroform extract. The mentioned results display that various solvents used for the extraction process contained a remarkable amount of TPC. A significant difference was observed at a level $p<0.05$ between the various extracts in the total phenolics content. The current results compromise with the prior studies confirm that one of the most efficient solvents to obtain phenolic compounds was alcohol, such as ethanol. The selected solvent can also specify the extraction capacity of phenolic compounds. Several studies have already confirmed the existence of phenolic compounds in A. euchroma extracts from ethanol $[13,17]$. All amounts measured were reported in Figure 4, and values displayed major variations in the studied extract's various solvents. One of the important components of plants is phenolic compounds, and due to the presence of these valuable components, it could have several pharmacological effects. Also, it can be advantageous for health and medical consumption. 
(a)

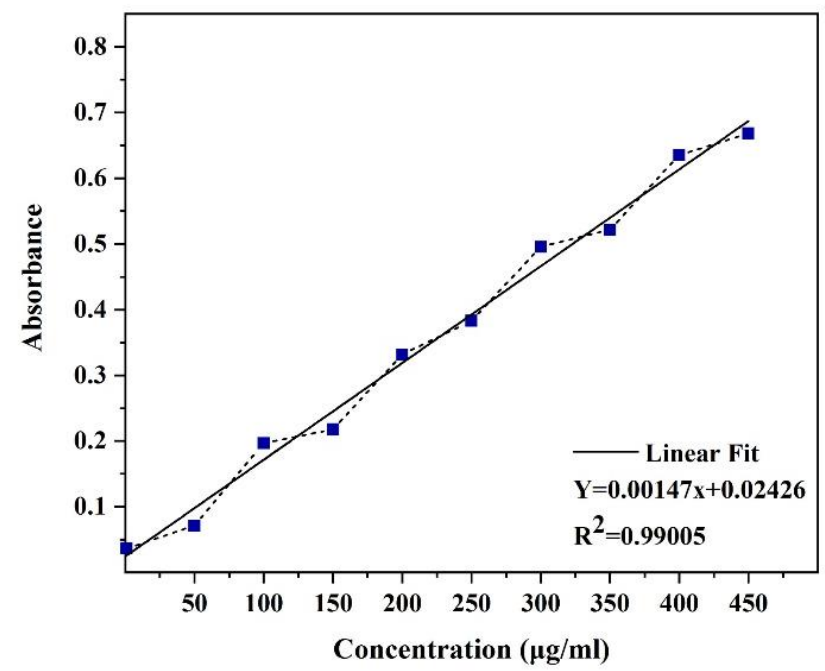

(b)

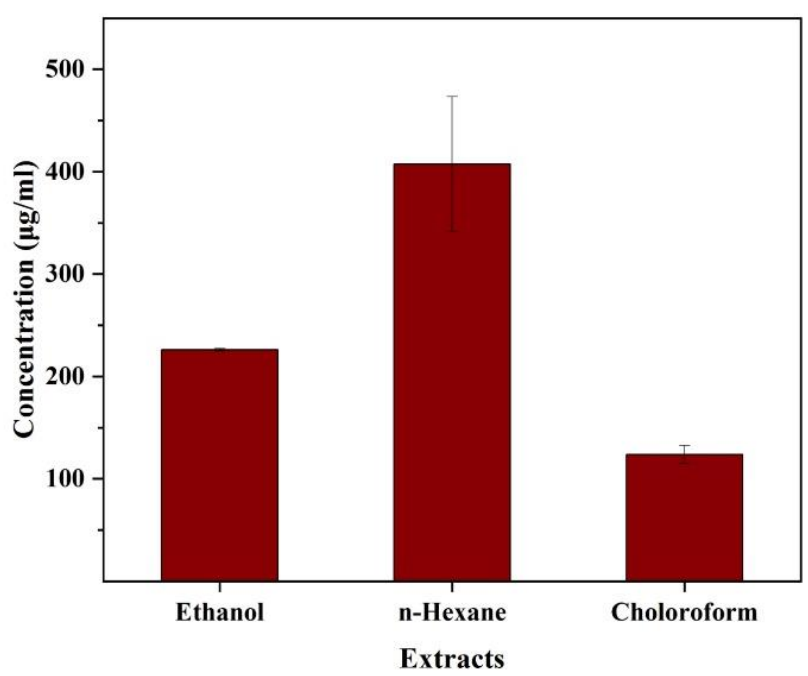

Figure 4. Total phenolic content of three different extracts of A. euchroma. (a) The standard gallic acid curve was constructed by preparing the dilutions of different concentrations (1, 50, 100, 150, 200, 250, 300, 350, 400, and $450 \mu \mathrm{g} / \mathrm{ml}$ ) in methanol (b) Total phenolic content (mean \pm SD) of extracts; the bars demonstrate the mean values of three independent experiment. The significant difference at $\mathrm{P}<0.05$ was viewed between ethanol vs. $\mathrm{n}$ hexane $\left(0.0028^{* *}\right)$, ethanol vs. chloroform $(0.0398 *)$, and n-hexane vs. chloroform $(0.0003 * * *)$.

\subsection{Evaluation of antioxidant activity.}

Superoxide is a reactive oxygen species that can cause cell and DNA damages and create different diseases. Phenolic, flavonoids, and carotenoids are secondary metabolites in plants that possess antioxidant activity due to their chemical structures and redox properties. Besides, phenolic compounds have responsible for adjusting oxidative stress tolerance on plants. All root extracts of $A$. euchroma with three various solvents had potent antioxidant activity against all the free radicals studied.

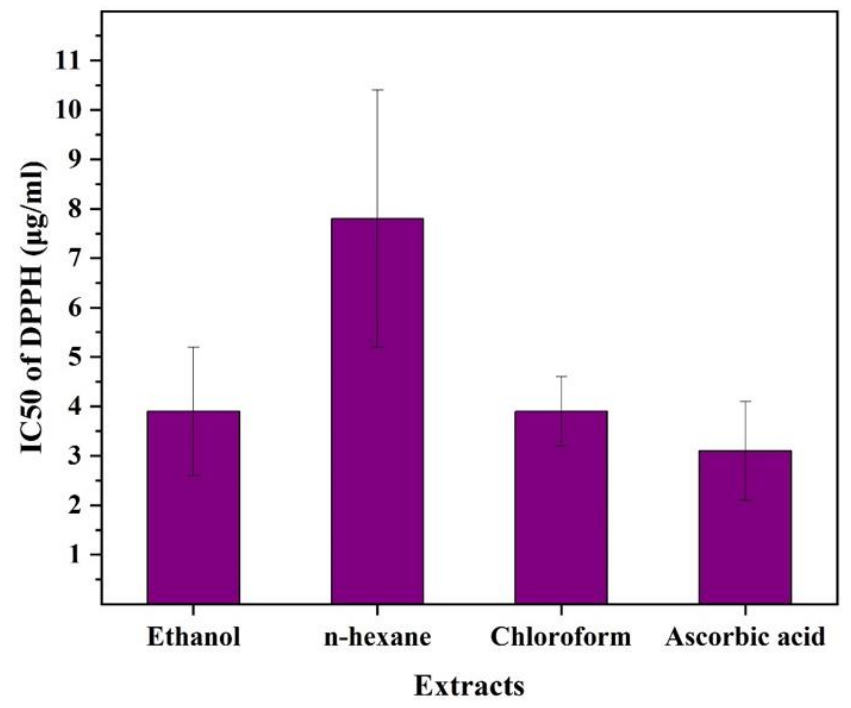

Figure 5. DPPH inhibition (antioxidant activity) of A. euchroma. (IC50 means the amount of material that can inhibit $50 \%$ of DPPH free radical.). The bars demonstrate the mean values of three independent experiments. No significant difference at $\mathrm{P}<0.05$ was viewed between in various extracts.

The DPPH radical is widely used in investigating free radical scavenging activity due to the simplicity of the reaction. The antioxidant properties of extracts confirmed that the antioxidant activity of Ethanol and Chloroform $(3.9 \mu \mathrm{g} / \mathrm{ml})$ was relatively higher than $\mathrm{n}$ - 
Hexane $(7.8 \mu \mathrm{g} / \mathrm{ml})$ extract (Figure 5). As demonstrated, the lower the IC50 values are, the higher the A. euchroma extracts' antioxidant capacity. Due to ascorbic acid's positive control, the results have shown that all extracts with various solvents have considerable antioxidant capacity. The high phenolic and flavonoid content in crude extracts plays a vital role in these plant's bioactivity. Crude extracts of herbal medicine and other plant materials possess phenolic and flavonoid compounds that can increasingly be used in the health, medical consumption, and pharmaceutical industry for their antioxidative properties.

\subsection{Total antioxidant capacity analysis.}

As shown in Figure 6, there were significant differences in total antioxidant capacity (FRAP) between the three various extracts. The FRAP values varied, and the significant difference (P-value <0.0001) was confirmed between three different extracts (Figure 6). However, no total antioxidant capacity was observed in the chloroform extract. Free radicals and reactive oxygen species are among the most critical issues in metabolism in the body. There is numerous biochemical, biological, and clinical evidence suggesting that the oxidative reaction of free radicals, which is cytotoxic, is involved in various diseases such as cancer, diabetes, cardiovascular disease, atherosclerosis, neurological diseases, and accelerated aging. There are multiple methods and protocols to measure antioxidant capacity. These methods vary in their assay and experimental conditions; thus, specific antioxidants possess different contributions to total antioxidant capacity. This paper has used FRAP assay because it is rapid and easy to perform, inexpensive, repeatable, and affordable to measure total antioxidant capacity. According to the results, the total antioxidant capacity of A. euchroma in three different extracts can be divided into three groups which include very low FRAP $(0.001 \pm 0.01$ $\mathrm{mmol} / \mathrm{L})$, good FRAP $(0.113 \pm 0.09 \mathrm{mmol} / \mathrm{L})$, high FRAP $(0.907 \pm 0.07 \mathrm{mmol} / \mathrm{L})$ respectively related to chloroform, n-Hexan, and ethanol. On the contrary, herbal medicine's affirmative properties with low FRAP value are unlikely to its antioxidant capacity.

(a)

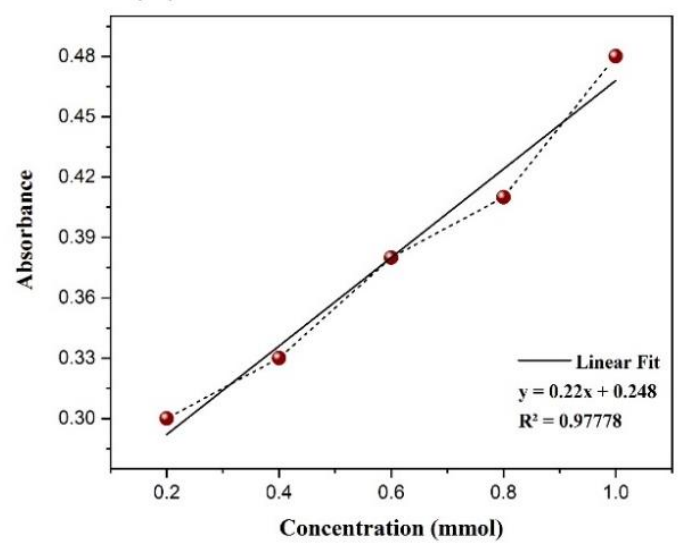

(b)

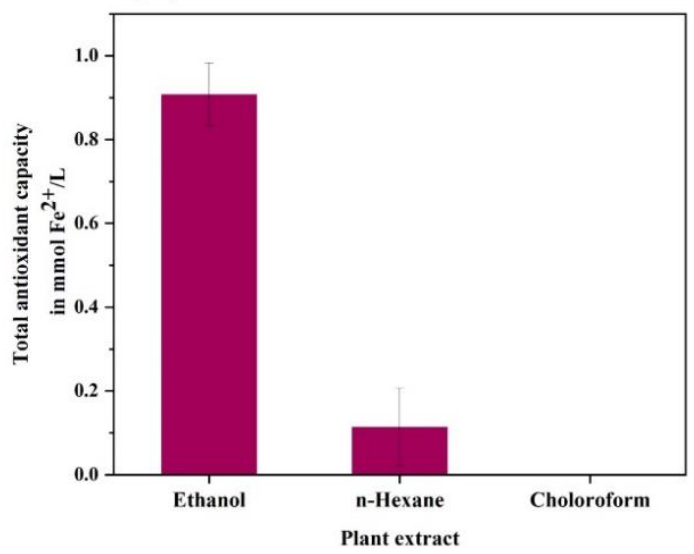

Figure 6. Total antioxidant capacity of three different extracts of A. euchroma, which has been analyzed by FRAP assay. (a) The standard curve was constructed by preparing the dilutions of different concentrations $(0$, $0.2,0.4,0.6,0.8$, and $1 \mathrm{mmol}$ ) (b) Total antioxidant capacity (mean \pm SD) of extracts; the bars demonstrate the mean values of three independent experiments. The significant difference at $\mathrm{P}<0.05$ was viewed between ethanol vs. n-hexane $(<0.0001 * * * *)$, ethanol vs. chloroform $(<0.0001 * * * *)$, and n-hexane vs. chloroform $\left(0.0318^{*}\right)$. 


\subsection{Antimicrobial activity.}

The antibacterial properties of three extracts of the roots of A. euchroma are represented in Figure 7. All extracts have antibacterial activity against Gram-positive and Gram-negative bacteria, with MICs of 300-700 $\mu \mathrm{g} / \mathrm{ml}$. MIC and MBC were carried out to investigate the antibacterial capacity of the A. euchroma. In our study, the MIC of Ethanol extract, Chloroform, and n-hexane for gram-positive and gram-negative bacterias were 700, 400, 400 $\mu \mathrm{g} / \mathrm{ml}$ for E. coli, 500, 500, $400 \mu \mathrm{g} / \mathrm{ml}$ for S. aureus, 400, 400, $300 \mu \mathrm{g} / \mathrm{ml}$ for S. epidermis and $400,300,300 \mu \mathrm{g} / \mathrm{ml}$ for $\mathrm{P}$. aeruginosa, respectively. According to the results, the $\mathrm{n}$-hexane and chloroform extracts have relatively revealed better inhibitory concentration. The chloroform extract displayed the lowest $\mathrm{MBC}$ at $600 \mu \mathrm{g} / \mathrm{ml}$ for E.Coli and S. aureus, whereas the lowest bactericidal activity for chloroform extract was $500 \mu \mathrm{g} / \mathrm{ml}$ for S. epidermis and P. aeruginosa. These results indicate that A. euchroma can act as a potential source of broad-spectrum antimicrobial agents. The extract's antimicrobial activity may be related to the high amount of secondary metabolites such as flavonoids, which have been reported to play a critical role in inhibiting nucleic acid biosynthesis and other processes [42]. Also, phenolic compounds possess a $\mathrm{C} 3$ side chain at a lower oxidation level and not comprising any oxygen have mostly been reported to act as antimicrobials agents [43]. The phenolic compounds have a partially hydrophobic nature that could be one reason for their antimicrobial activity. Moreover, the main mechanism of the toxicity of phenolic compounds against microorganisms is the inhibition of hydrolytic enzymes or other interactions that can inactivate microbial adhesins, non-specific interactions with carbohydrates and cell envelope transport proteins [44, 45].

(a)

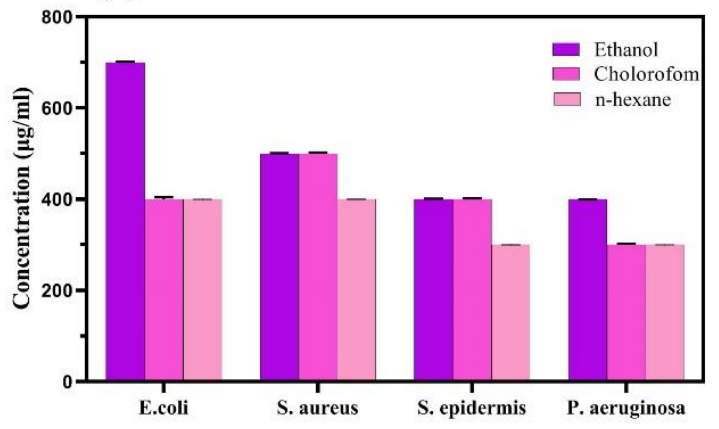

(b)

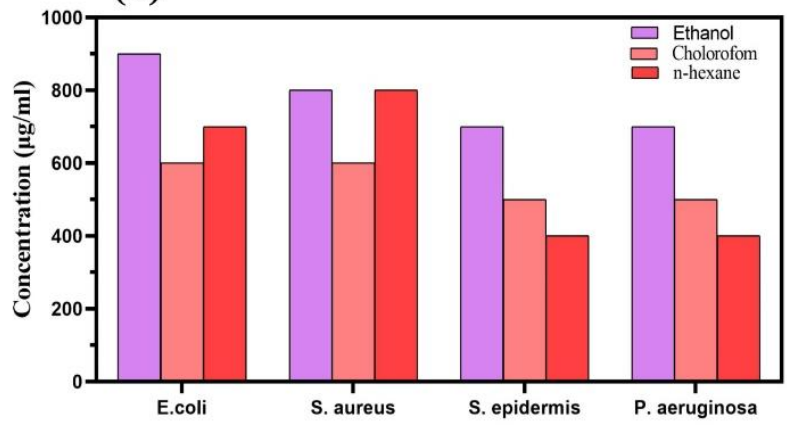

Figure 7. MIC (a) and MBC (b) of three extracts against gram-positive and gram-negative bacteria; the bars demonstrate the mean values of three independent experiments. The significant difference at $\mathrm{P}<0.05$ was viewed between $(<0.0001 * * * *)$ and ns (none significant) in some groups.

\subsection{Analysis of SEM images of Bacteria.}

SEM imaging is the selected method for analyzing the bare surfaces and the morphological changes on the bacterial cells before and after exposure to A. euchroma. The control sample or untreated P.Aeruginosa bacteria prepared for SEM micrographs were approximately 1.5-2.5 $\mu \mathrm{m}$ long and showed a smooth, intact structure and morphology, undamaged and rod-shaped (Figure $8 \mathrm{a}-\mathrm{b}$ ). Also, scanning Electron Microscopy images of the bacterial cell is viewed as a single form and uniform structure. In a few bacterial cells, their surface looked corrugated, and also, there were some dimples in these cells, but their length remained the same. After incubation with MICs of extract, the bacteria approximately shortened to as little as one $\mu \mathrm{m}$ and significantly increased their surface roughness with a considerable number of microscale dimples and protrusions (Figure $8 \mathrm{c}-\mathrm{d}$ ), indicates that P.Aeruginosas structure has been damaged and cannot grow and divided properly. 
Along with the dimples on the surface of the bacteria cells in the treated group and wrinkling morphology were seen after exposure to the MIC of concentrations of the extract. The bacteria that were incubated with MIC of extracts had holes in the cell wall that caused multiple dents and lysed many cells (data not shown). After treating bacteria with extract, SEM imaging showed that the bacteria had burst with deep craters in their cell wall (Fig.8 d) and also lysed.
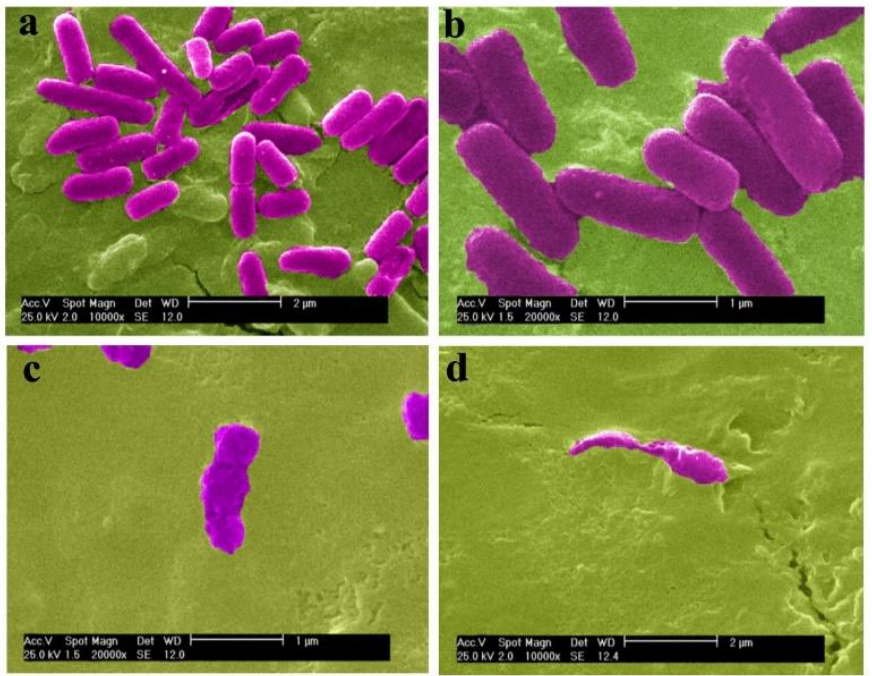

Figure 8. SEM micrographs of untreated P.Aeruginosas (a) and (b) the cells are undamaged and intact. After treatment with MIC of extract, in the morphology of bacteria, some dents and dimple (c) can be seen, and the structure of bacteria has completely been wrinkled (d). Some deep craters and bursts are observed, and entirely lysed bacteria are seen in the picture. The SEM images were sputter-coated with gold. (The micrograph was converted into the RGB color mode from grey color and further converted into the indexed color mode.)

\section{Conclusions}

This work highlights the vital difference in chemical and phytochemical composition among the three various extracts of A. euchroma and their considerable influence on biological activities and medicinal aspects. Our present study aimed to characterize the LC-MS profile, fingerprint of extracts phytochemical, total phenolic content, antioxidant and antibacterial activities which bioactive compounds are responsible for these activities. According to the LCMS analysis, which was interpreted through the SDBS database, some of the various extract's compounds were determined. These data can be used to define and classify the structure elucidation of phenolic compounds, which is a primary step towards realizing their importance that acts as natural antioxidants. The DPPH assay results, it was proved that methanol, chloroform and n-Hexane extracts of A. euchroma had an excellent antioxidant activity with IC50 of $3.9 \mu \mathrm{g} / \mathrm{mL}$ and $7.8 \mu \mathrm{g} / \mathrm{mL}$, respectively, which confirm total phenolic content results. High phenolic content of n-Heane extracts of A. euchroma can cause well antioxidant activity against free radicals and reactive oxygen species in biological systems. Based on these results, it can be concluded that ethanol and n-Hexane extracts of A. euchroma had great potential as biomedicine and pharmaceuticals to treat many diseases. Also, all extracts are endowed with potent antimicrobial activities. Our results may be stated that secondary metabolites and the active component can be detected in extracts of A. euchroma, which may serve as a characteristic "fingerprint" identified by HPTLC and UV-spectroscopy that confirm a wide range of pharmacological activity. The present findings suggest that this extract could be a prominent and potent source of medicinally main natural compounds. 


\section{Funding}

This research was funded by Tehran University of Medical Sciences and Health Services (TUMS), grant no 41008. https://search.crossref.org/funding, any errors may affect your future funding.

\section{Acknowledgments}

This work was supported by the Department of Medical Nanotechnology, School of Advanced Technologies in Medicine, Tehran University of Medical Sciences, and as well as the authors thank for all the support provided.

\section{Conflicts of Interest}

The authors declare no conflict of interest.

\section{References}

1. Kaith, B; Kaith, N; Chauhan, N. Anti-inflammatory effect of Arnebia euchroma root extracts in rats. $J$ Ethnopharmacol. 1996, 55, 77-80, https://doi.org/10.1016/S0378-8741(96)01477-8.

2. Chawla, K; Mopuri, R; Sharma, AK; Kumar, P. Arnebia euchroma. In: Himalayan Medicinal Plants: Advances in Botany, Production \& Research 2021, 27-41, https://doi.org/10.1016/B978-0-12-8231517.00002-7.

3. Naz, S; Ahmad, S; Rasool, SA; Sayeed, SA; Siddiqi, R. Antibacterial activity directed isolation of compounds from Onosma hispidum. Microbiol Res. 2006, 161, 43-48, https://doi.org/10.1016/j.micres.2005.05.001.

4. Kumar, A; Shashni, S; Kumar, P; Pant, D; Singh, A; Verma, RK. Phytochemical constituents, distributions and traditional usages of Arnebia euchroma: a review. J Ethnopharmacol. 2021, 271, 113896, https://doi.org/10.1016/j.jep.2021.113896.

5. Sasaki, K; Abe, H; Yoshizaki, F. In vitro antifungal activity of naphthoquinone derivatives. Biol Pharm Bull. 2002, 25, 669-670, https://doi.org/10.1248/bpb.25.669.

6. Singh, LK; Maheshwari, DK; Shukla, S. Antibacterial effect of butyryl alkannin from Arnebia euchroma against vancomycin-resistant pathogens of Enterococcus faecalis causing urinary tract infections. Natural product research 2015, 29, 2299-2301, https://doi.org/10.1080/14786419.2015.1004676.

7. Shen, C-C; Syu, W-J; Li, S-Y; Lin, C-H; Lee, G-H; Sun, C-M. Antimicrobial activities of naphthazarins from arnebia e uchroma. J Nat Prod. 2002, 65, 1857-1862, https://doi.org/10.1021/np010599w.

8. Sharma, N; Gulati, A. Selective binding of $\mathrm{Ni} 2+$ and $\mathrm{Cu} 2+$ metal ions with naphthazarin esters isolated from Arnebia euchroma. Biotechnol Prog. 2020, 36, e2985, https://doi.org/10.1002/btpr.2985.

9. Pirbalouti, AG; Yousefi, M; Nazari, H; Karimi, I; Koohpayeh, A. Evaluation of burn healing properties of Arnebia euchroma and Malva sylvestris. Electronic Journal of Biology 2009, 5, 62-66.

10. Liu, B; Jin, J; Zhang, Z; Zuo, L; Jiang, M; Xie, C. Shikonin exerts antitumor activity by causing mitochondrial dysfunction in hepatocellular carcinoma through PKM2-AMPK-PGC1 $\alpha$ signaling pathway. Biochem Cell Biol. 2019, 97, 397-405, https://doi.org/10.1139/bcb-2018-0310.

11. Damianakos, H; Kretschmer, N; Sykłowska-Baranek, K; Pietrosiuk, A; Bauer, R; Chinou, I. Antimicrobial and cytotoxic isohexenylnaphthazarins from Arnebia euchroma (Royle) Jonst.(Boraginaceae) callus and cell suspension culture. Molecules 2012, 17, 14310-14322, https://doi.org/10.3390/molecules171214310.

12. Papageorgiou, VP; Assimopoulou, AN; Couladouros, EA; Hepworth, D; Nicolaou, K. The chemistry and biology of alkannin, shikonin, and related naphthazarin natural products. Angewandte Chemie International Edition 1999, 38, 270-301. https://doi.org/10.1002/(SICI)1521-3773(19990201)38:3<270::AIDANIE270>3.0.CO;2-0.

13. Cao, H; Zhang, W; Liu, D; Hou, M; Liu, S; He, W; Lin, J; Shao, M. Identification, in vitro evaluation and modeling studies of the constituents from the roots of Arnebia euchroma for antitumor activity and STAT3 inhibition. Bioorg Chem. 2020, 96, 103655, https://doi.org/10.1016/j.bioorg.2020.103655.

14. Chen, Y; Si, L; Zhang, J; Yu, H; Liu, X; Chen, Y; Wu, Y. Uncovering the antitumor effects and mechanisms of Shikonin against colon cancer on comprehensive analysis. Phytomedicine 2021, 82, 153460, https://doi.org/10.1016/j.phymed.2021.153460. 
15. Chen, M; Vial, M; Gee, L; Davis, R; St John, J; Ekberg, J. The plant natural product 2-methoxy-1, 4naphthoquinone stimulates therapeutic neural repair properties of olfactory ensheathing cells. Sci Rep. 2020, 10, 1-15, https://doi.org/10.1038/s41598-020-57793-2.

16. Ozgen, U; Ikbal, M; Hacimuftuoglu, A; Houghton, P; Gocer, F; Dogan, H; Coskun, M. Fibroblast growth stimulation by extracts and compounds of Onosma argentatum roots. J Ethnopharmacol. 2006, 104, 100-103, https://doi.org/10.1016/j.jep.2005.08.052.

17. Liu, H; Jin, Y-S; Song, Y; Yang, X-N; Yang, X-W; Geng, D-S; Chen, H-S. Three new compounds from Arnebia euchroma. Journal of Asian natural products research 2010, 12, 286-292, https://doi.org/10.1080/10286021003743861.

18. Kumar, R; Malik, S; Bhushan, S; Sharma, UK; Kumari, D; Sinha, AK; Sharma1, M; Ahuja1, PS. Cell suspension culture of Arnebia euchroma (Royle) Johnston A potential source of naphthoquinone pigments. Journal of Medicinal Plants Research 2011, 5, 6048-6054, https://doi.org/10.5897/JMPR11.925.

19. Sykłowska-Baranek, K; Pilarek, M; Cichosz, M; Pietrosiuk, A. Liquid perfluorodecalin application for in situ extraction and enhanced naphthoquinones production in Arnebia euchroma cell suspension cultures. Appl Biochem Biotechnol. 2014, 172, 2618-2627, https://doi.org/10.1007/s12010-013-0701-5.

20. Yao, X-S; Ebizuka, Y; Noguchi, H; Kiuchi, F; Shibuya, M; Iitaka, Y; Seto, H; Sankawa ,U. Biologically active constituents of Arnebia euchroma: structure of arnebinol, an ansa-type monoterpenylbenzenoid with inhibitory activity on prostaglandin biosynthesis. Chem Pharm Bull (Tokyo) 1991, 39, 2956-2961, https://doi.org/10.1248/cpb.39.2956.

21. Roeder, E; Rengel-Mayer, B. Pyrrolizidine alkaloids from Arnebia euchroma. In: GEORG THIEME VERLAG PO BOX $30 \quad 11$ 20, D-70451 STUTTGART, GERMANY, 1993, 192-192, https://doi.org/10.1055/s-2006-959647.

22. Okeke, IN; Lamikanra, A; Edelman, R. Socioeconomic and behavioral factors leading to acquired bacterial resistance to antibiotics in developing countries. Emerg Infect Dis. 1999, 5, 18, https://doi.org/10.3201/eid0501.990103.

23. Giono-Cerezo, S; Santos-Preciado, JI; Morfín-Otero, MDR; Torres-López, FJ; Alcántar-Curiel, MD. Antimicrobial resistance. Its importance and efforts to control it. Gac Med Mex. 2020, 156, 171-178. https://doi.org/10.24875/GMM.M20000358.

24. Evans, CE; Banso, A; Samuel, OA. Efficacy of some nupe medicinal plants against Salmonella typhi: an in vitro study. J Ethnopharmacol. 2002, 80, 21-24, https://doi.org/10.1016/S0378-8741(01)00378-6.

25. Chang, M-J; Huang, G-J; Ho, Y-L; Lin, I-H; Huang, S-S; Chang, T-N; Chang, H-Y; Chang, Y-S. Study on the antioxidant activities of crude extracts from the roots of Arnebia euchroma and Lithospermum erythrorhizon. Extraction 2008, 7, 10-56.

26. Ames, BN; Shigenaga, MK; Hagen, TM. Oxidants, antioxidants, and the degenerative diseases of aging. Proceedings of the National Academy of Sciences. 1993, 90, 7915-7922, https://doi.org/10.1073/pnas.90.17.7915.

27. Hogg, N. Free radicals in disease. In: Semin Reprod Endocrinol. Thieme Medical Publishers, Inc. 1998, 241248, https://doi.org/10.1055/s-2007-1016284.

28. Pyo, Y-H; Lee, T-C; Logendra, L; Rosen, RT. Antioxidant activity and phenolic compounds of Swiss chard (Beta vulgaris subspecies cycla) extracts. Food chemistry 2004, 85, 19-26, https://doi.org/10.1016/S03088146(03)00294-2.

29. Gul, R; Jan, SU; Faridullah, S; Sherani, S; Jahan, N. Preliminary phytochemical screening, quantitative analysis of alkaloids, and antioxidant activity of crude plant extracts from Ephedra intermedia indigenous to Balochistan. The Scientific World Journal 2017, https://doi.org/10.1155/2017/5873648.

30. Maliński, MP; Kikowska, MA; Soluch, A; Kowalczyk, M; Stochmal, A; Thiem, B. Phytochemical Screening, Phenolic Compounds and Antioxidant Activity of Biomass from Lychnis flos-cuculi L. In Vitro Cultures and Intact Plants. Plants 2021, 10, 206, https://doi.org/10.3390/plants10020206.

31. Bader, A; Omran, Z; Al-Asmari, AI; Santoro, V; De Tommasi, N; D’Ambola, M; Dal Piaz, F; Conti, B; Bedini, S; Halwani, M. Systematic Phytochemical Screening of Different Organs of Calotropis procera and the Ovicidal Effect of Their Extracts to the Foodstuff Pest Cadra cautella. Molecules 2021, 26, 905, https://doi.org/10.3390/molecules26040905.

32. Kaur, C; Kapoor, HC. Anti-oxidant activity and total phenolic content of some Asian vegetables. International Journal of Food Science \& Technology 2002, 37, 153-161, https://doi.org/10.1046/j.13652621.2002.00552.x.

33. Aissani, F; Grara, N; Bensouici, C; Bousbia, A; Ayed, H; Idris, M.H.M; Teh, L.K. Algerian Sonchus oleraceus L.: a comparison of different extraction solvent on phytochemical composition, antioxidant properties and anti-cholinesterase activity. Advances in Traditional Medicine 2021, 1-12, https://doi.org/10.1007/s13596-021-00553-y. 
34. Brand-Williams, W; Cuvelier, M-E; Berset, C. Use of a free radical method to evaluate antioxidant activity. LWT-Food science and Technology 1995, 28, 25-30, https://doi.org/10.1016/S0023-6438(95)80008-5.

35. Ginting, CN; Lister, INE; Girsang, E; Riastawati, D; Kusuma, HSW; Widowati, W. Antioxidant Activities of Ficus elastica Leaves Ethanol Extract and Its Compounds. Molecular and Cellular Biomedical Sciences 2020, 4, 27-33, https://doi.org/10.21705/mcbs.v4i1.86.

36. Katalinic, V; Milos, M; Kulisic, T; Jukic, M. Screening of 70 medicinal plant extracts for antioxidant capacity and total phenols. Food chemistry 2006, 94, 550-557, https://doi.org/10.1016/j.foodchem.2004.12.004.

37. Gacem, MA; Telli, A; Gacem, H; Ould-El-Hadj-Khelil, A. Phytochemical screening, antifungal and antioxidant activities of three medicinal plants from Algerian steppe and Sahara (preliminary screening studies). SN Applied Sciences 2019, 1, 1-13, https://doi.org/10.1007/s42452-019-1797-1.

38. JH. TSTaOaNaTa. Spectral Database for Organic Compounds, SDBS. In; 2018, https://sdbs.db.aist.go.jp/sdbs/cgi-bin/direct_frame_top.cgi.

39. Shivatare, RS; Nagore, DH; Nipanikar, SU. HPTLC'an important tool in standardization of herbal medical product: A review. Journal of scientific and innovative research 2013, 2, 1086-1096.

40. Lim, SM; Agatonovic-Kustrin, S; Lim, FT; Ramasamy, K. High-performance thin layer chromatographybased phytochemical and bioactivity characterisation of anticancer endophytic fungal extracts derived from marine plants. J Pharm Biomed Anal. 2021, 193, 113702, https://doi.org/10.1016/j.jpba.2020.113702.

41. Singleton, VL; Orthofer, R; Lamuela-Raventós, RM. [14] Analysis of total phenols and other oxidation substrates and antioxidants by means of folin-ciocalteu reagent. Methods Enzymol. 1999, 299, 152-178, https://doi.org/10.1016/S0076-6879(99)99017-1.

42. Cushnie, T; Lamb, A. Antimicrobial activity of flavonoids. International Journal of Antimicrobial Agents 2005, 26, 343-56, https://doi.org/10.1016/j.ijantimicag.2005.09.002.

43. Berkarda, B. Preliminary report: Warfarin for treatment of Herpes simplex. Journal-Irish Colleges of Physicians and Surgeons 1993, 22, 56-56.

44. Pyla, R; Kim, T-J; Silva, JL; Jung, Y-S. Enhanced antimicrobial activity of starch-based film impregnated with thermally processed tannic acid, a strong antioxidant. Int J Food Microbiol. 2010, 137, 154-160, https://doi.org/10.1016/j.ijfoodmicro.2009.12.011.

45. Amer, MW; Awwad, AM. Green synthesis of copper nanoparticles by Citrus limon fruits extract, characterization and antibacterial activity. Chem Int. 2021, 7, 1-8, https://doi.org/10.5281/zenodo.4017993. 